\title{
Rx: A dose of ethics to revive trust in medical practice
}

\author{
Anita Jain India editor, BMJ
}

Mumbai

Gold jewellery? Cars and air conditioners to survive the sweltering Indian summer, or an exotic foreign trip to escape it? These are among the luxury gifts listed in a parliamentary committee report as being used by pharmaceutical companies to coax doctors into prescribing their drugs. In a $B M J$ feature on this topic (doi:10.1136/bmj.f2635), C M Gulati, editor of the Monthly Index of Medical Specialties, crisply lays out a 3C strategy employed by drug companies: "convince if possible, confuse if necessary, and corrupt if nothing else works."

Medical representatives queuing up outside doctors' clinics are a common sight in any Indian city or town. Doctors often rely on them for information on the latest drugs and devices in their specialty. In a relationship that acquires dimensions of complicity over time, doctors may demand the latest foreign textbooks, journal subscriptions, and conference registrations from medical reps in exchange for prescribing their brand.

Although many will say an emphatic no to luxury gifts, I wonder what you think of the acquisition of educational tools facilitated by drug companies. How may we ensure that resources we seek to advance the care of our patients do not inadvertently harm them-even financially? With $78 \%$ of healthcare expenses in India being borne by patients out of their pockets, cost of medicines is a major determinant in their ability to start or continue treatment. In the latest poll on bmj.com we seek to understand where you stand on this issue: "Is it ethical for doctors to take gifts from drug companies?"

Strict government regulation of drug companies and doctors is being advocated as a countermeasure. As the debate continues in India, it was truly refreshing to learn of cancer specialists around the world rising in unison against the "immoral profiteering" by drug companies that makes life saving cancer drugs inaccessible and unsustainable for patients (doi:10.1136/ bmj.f2810). To me, this movement provides an example of doctors leading medicine in the right direction. This kind of stance must be our raison d'être, and may help redeem the lost sheen of our profession in the eyes of those who count on us. Regulation and punitive measures may have a place, but they are inadequate. A foundation of ethical practice and a patient centred approach in doctors is the key to such a motion.

With this vision, health activists in India have for a long time been advocating for training in ethics to be integrated into the medical curriculum. So it is a victory for them, and for medical practice at large, that the Medical Council of India has now formally committed to this change (doi:10.1136/bmj.f2794). The impact may take years to become evident, but this step is worth celebrating.

This development is doubly relevant in view of the prevailing climate of commercialization of healthcare, which has led to a breakdown of trust in the doctor-patient relationship. This trend is not limited to drug prescribing; the business of "cut practice," or kickbacks for referrals, is a known secret. With the mushrooming of hi-tech diagnostic and specialist centres in urban India, it is vital to question whether referral decisions are truly essential and evidence based.

Interestingly, several papers nominated for the $B M J$ best research paper award this year explore this very dimension of overdiagnosis and overtreatment. Topics include watchful waiting over radical prostatectomy and the benefits (or not) of general health checks and population-based type 2 diabetes screening (doi:10.1136/bmj.f2512). Watch out for the winning paper at the annual BMJ Improving Health Awards, to be held on 9th May. After the celebrations are over, I hope that the findings of such research can be translated into practice to guide ethical clinical decision making.

Follow Anita Jain on Twitter @ajain247

Cite this as: BMJ 2013;346:f2987

๑ BMJ Publishing Group Ltd 2013 